\title{
Prevalence and associated factors of HIV testing among reproductive-age women in eastern Africa: multilevel analysis of demographic and health surveys
}

Misganaw Gebrie Worku ${ }^{1 *}$ (D) Getayeneh Antehunegn Tesema² and Achamyeleh Birhanu Teshale ${ }^{2}$

\begin{abstract}
Background: Despite efforts made to reduce the spread of the human immune-deficiency virus (HIV), its testing coverage remains low in low and middle-income countries (LMIC). Besides, information on factors associated with HIV counseling and testing among reproductive-age women is not sufficiently available. Therefore, this study was aimed to determine the pooled prevalence and factors associated with HIV testing among reproductive-age women in eastern Africa.

Methods: Secondary data analysis was conducted based on the Demographic and Health Surveys (DHS) data conducted in East African countries. We pooled the most recent DHS surveys done in 11 East African countries. A total weighted sample of 183,411 reproductive-age women was included for this study. Both bivariable and multivariable multilevel logistic regression models were fitted. Variables with a $p$-value $\leq 0.2$ in the bivariable analysis were selected for multivariable analysis. Finally, in the multivariable analysis, variables with a $p$-value $\leq 0.05$ were considered as significant factors affecting HIV testing.

Results: The pooled prevalence of HIV testing in eastern Africa was $66.92 \%$ (95\%Cl: 66.70, 67.13\%). In the multivariable multilevel analysis factors such as the age of respondent, marital status, educational level, HIV knowledge, HIV stigma indicator, risky sexual behavior and women who visit a health facility were positively associated with HIV testing coverage among reproductive-age women. While women from rich and richest households, having multiple sexual partners, being from rural dwellers, late initiation of sex and higher community illiteracy level had a lower chance of being tested for HIV.
\end{abstract}

\footnotetext{
* Correspondence: misgeb2008@gmail.com

'Department of Human Anatomy, College of Medicine and Health Science, School of Medicine, University of Gondar, Gondar, Ethiopia

Full list of author information is available at the end of the article
}

(c) The Author(s). 2021 Open Access This article is licensed under a Creative Commons Attribution 4.0 International License, which permits use, sharing, adaptation, distribution and reproduction in any medium or format, as long as you give appropriate credit to the original author(s) and the source, provide a link to the Creative Commons licence, and indicate if changes were made. The images or other third party material in this article are included in the article's Creative Commons licence, unless indicated otherwise in a credit line to the material. If material is not included in the article's Creative Commons licence and your intended use is not permitted by statutory regulation or exceeds the permitted use, you will need to obtain permission directly from the copyright holder. To view a copy of this licence, visit http://creativecommons.org/licenses/by/4.0/ The Creative Commons Public Domain Dedication waiver (http://creativecommons.org/publicdomain/zero/1.0/) applies to the data made available in this article, unless otherwise stated in a credit line to the data. 
Conclusion: The pooled prevalence of HIV testing in eastern Africa was higher than most previous studies. Age of respondent, residence, wealth index, marital status, educational level, HIV knowledge, stigma indicator, risky sexual behavior, women who visit a health facility, multiple sexual partnerships, early initiation of sex and community illiteracy level were significantly associated with HIV testing. There should be an integrated strategic plan to give education about methods of HIV transmission and the implication of HIV testing and counseling. So all the stakeholders should have an integrated approach by giving special attention to the factors that hinder HIV testing to increase awareness regarding the benefit of HIV testing and counseling to control the spread of HIV/AIDS.

Keywords: Multi-level analysis, HIV/AIDS, HIV testing, Eastern Africa

\section{Background}

Human immune deficiency virus (HIV) testing and counseling is a public health program concerned with diagnosing and minimizing the transmission of $\mathrm{HIV} /$ AIDS [1]. Currently, about 38 million people are living with HIV, nearly 36.2 million of them are adults and 1.8 million children [2]. Globally, $81 \%$ of all people living with HIV know their status and about 19 million remained unaware of their HIV status, which reduced to 7.1 million in 2019 [1]. The number of people who are newly infected with HIV declined from 3.4 million in 2011 to 2.1 million in 2013 [1]. Despite this progress, HIV/AIDS remains a major public health problem [3]. African countries, particularly eastern and southern regions are greatly affected by HIV/AIDS, which accounts for two-thirds of total new infections $[4,5]$.

Voluntary counseling and testing are considered as an initial step to detect, treat and prevent HIV/AIDS [6, 7]. The World Health Organization recommends HIV testing and counseling for all patients showing signs and symptoms of the disease [1, 8]. In Africa HIV testing coverage ranges from 33.5 to $82.3 \%$ [9-12].

According to studies conducted in different parts of the world age of the respondent, having multiple sexual partnerships, early initiation of sex, level of education, marital status and socio-economic status are some of the factors that are significantly associated with HIV testing [7, 10, 13, 14]. Besides, stigmatized attitudes, levels of knowledge about HIV/AIDS and risky sexual behavior have an association with HIV testing and counseling [7, 12, 13, 15-19].

Even though HIV testing is very crucial for all strategies related to care, prevention and treatment of HIV/ AIDS, it is less practiced among reproductive-age women, particularly in developing countries $[6,16]$. Every individual needs to know their HIV status for the benefit of themselves and others [1, 20, 21]. Although global efforts had made to reduce the spread of HIV/ AIDS, its testing coverage remains low in developing countries [2]. The assessment and identification of factors that affect the utilization of HIV counseling and testing help policymakers to design effective strategies towards preventing and controlling HIV/ADIS. Besides, previous studies were conducted at a country level, most of them did not assess the community-level factors, which might be related to HIV testing coverage. Therefore, this study aimed to assess the pooled prevalence and factors associated with HIV testing among reproductive-age women in eastern Africa.

\section{Methods}

\section{Data sources}

This study was a secondary data analysis based on datasets from the most recent Demographic and Health Surveys (DHS) conducted in east Africa (Burundi, Ethiopia, Comoros, Uganda, Rwanda, Mozambique, Madagascar, Zimbabwe, Kenya, Zambia, and Malawi). The DHS is a nationally representative survey that collects data on basic health indicators like mortality, morbidity, family planning service utilization, fertility, maternal and child health. Each survey used a two-stage stratified sampling technique to select the study participants. We pooled the most recent DHS data done in 11 East African countries and a total weighted sample of 183,411 reproductive-age women was included for this study. The survey year and total weighted sample included for this study were presented in Table 1.

Table 1 Showing the survey year and total weighted sample for each country

\begin{tabular}{lll}
\hline Country & Year of survey & Weighted sample \\
\hline Burundi & 2016 & 17269 \\
Ethiopia & 2016 & 15683 \\
Kenya & 2014 & 31079 \\
Comoros & 2012 & 5329 \\
Madagascar & 2008 & 17375 \\
Malawi & $2015 / 16$ & 24562 \\
Mozambique & 2011 & 3061 \\
Rwanda & 2352 & 13497 \\
Uganda & 2016 & 4264 \\
Zambia & 2018 & 16411 \\
Zimbabwe & $2013 / 2014$ & 9955 \\
Total & & 183,411 \\
\hline
\end{tabular}




\section{Variables}

The outcome variable of this study was "ever been tested for HIV" which was coded as " 0 " for no and " 1 " for yes.

The independent variables included in this study were categorized as individual and community-level factors. The individual-level factors included were: age of respondent, marital status, age at 1st sex, stigmatized attitude, educational level, household wealth status, HIV knowledge, risky sexual behavior, visiting of health facility and multiple sexual partnerships. The communitylevel factors were community illiteracy level and residence. The community illiteracy level of women was generated by aggregating the individual level factor women's educational level by considering the proportion of women in the community that did not have formal education and by categorized this proportion as high and low based on the national median value.

\section{Operational definition}

\section{HIV knowledge}

It was generated based on three questions related to HIV prevention and three questions related to the modes of HIV transmission and graded as low (if a woman answered $\leq 3$ questions correctly), high (if a woman answered 4-5 questions correctly) or comprehensive (if a woman answered all the 6 questions correctly) [22].

\section{Risky sexual behaviors}

Assessed based on the five questions; having had STI in last 12 months, genital sore/ulcer in last 12 months, genital discharge in last 12 months, having at least one sexual partner other than the husband in the last 12 months, and multiple lifetimes sexual partnership. These were combined into an index of risky sexual behavior with three categories: "No risk" (if the response is no for all questions), "Some risk" (if the response is yes for one of the five questions) and "High risk" (if the response is yes to at least two questions) [22].

\section{HIV stigma indicator}

Six questions, which indicate negative attitudes towards people living with HIV / AIDS were used to this variable. This was categorized as "No stigma" (if we got a score of 6), "Low stigma" (if we got a score of 4-5), "Moderate stigma" (if we got a score of 2-3), and "High stigma" (if we got only score 1) [22].

\section{Data management and analysis}

Data extraction, recoding and analysis were done using STATA version 14 software. Both descriptive and analytical analyses were conducted. The data were weighted before doing statistical analysis to restore the representativeness of the data and to get a reliable estimate and standard error. Because of the hierarchical structure of the DHS data, a multilevel binary logistic regression analysis was used. The Interclass Correlation Coefficient (ICC), Proportional Change in Variance (PCV) and Median Odds Ratio (MOR) were calculated to assess whether there was clustering or not. In this study, four models have fitted; the null model- a model without explanatory variables, model I- a model with individuallevel factors, model II- a model with community-level factors and model III- a model with both individual and community-level factors. Model comparison was done based on deviance. Both bivariable and multivariable multi-level logistic regression were done. At the bivariable analysis variables with a $p$-value $\leq 0.2$ were considered for multivariable analysis. Finally, variables with a $P$-value of $\leq 0.05$ in the multivariable analysis were considered as a significant factor associated with HIV testing among reproductive-age women.

\section{Results}

Socio-demographic characteristics of study participants

A total weighted sample of 183, 411 reproductive-age women were included. About $21.54 \%$ of women were in the age group of 19 years and below. The majority $(92.13 \%)$ of women initiated sex at an earlier age and more than half $(56.82 \%)$ of them had visited health facilities in the last 12 months. Nearly, half (48.65\%) of the study participants attained primary education. Regarding HIV knowledge, about $47.81 \%$ of respondents had comprehensive knowledge about HIV/AIDS and most (60.49\%) of them had multiple sexual partnerships. Concerning risky sexual behavior, the majority $(81.70 \%)$ of the participant had no risky sexual behavior and $71.96 \%$ of the participants were rural dwellers (Table 2).

\section{Prevalence of HIV testing in eastern Africa}

The pooled prevalence of HIV testing in eastern Africa was 66.92\% (95\%CI: 66.70, 67.13\%) ranged from $7.56 \%$ in Madagascar to $85.74 \%$ in Rwanda (Fig. 1).

\section{Random effect model and model fitness}

As shown in Table 2, the ICC value in the null model was 0.10 , which indicates that about $10 \%$ of the total variation in HIV testing coverage was attributable to cluster variability. Besides, the MOR value in the null model was 1.77 , which indicates that there was a significant clustering of HIV testing among reproductive-age women. Furthermore, the PCV $(0.36)$ in the final model (model III) indicated that about $36 \%$ of the variation in HIV testing was explained by both individual and community-level factors. The final model (Model III) was the best-fitted model since it had the lowest deviance (Table 3). The model predictive ability was assessed using the Area Under the Curve (AUC) and Receiver 
Table 2 Sociodemographic characteristics of the respondents in eastern Africa $(N=183,411)$

\begin{tabular}{ll}
\hline Variables & Frequency (\%) \\
\hline Age (years) & \\
$15-19$ & $39,510(21.54 \%)$ \\
$20-24$ & $34,150(18.62 \%)$ \\
$25-29$ & $31,766(17.32 \%)$ \\
$30-34$ & $26,992(14.72 \%)$ \\
$35-39$ & $21,886(11.93 \%)$ \\
$40-44$ & $16,406(8.94 \%)$ \\
$45-49$ & $12,701(6.92 \%)$ \\
Highest education level & \\
No education & $33,035(18.01 \%)$ \\
Primary education & $89,229(48.65 \%)$ \\
Secondary education & $51,294(27.97 \%)$ \\
Higher education & $9,840(5.37 \%)$ \\
Wealth index & \\
Poorest & $32,495(17.72 \%)$ \\
Poorer & $33,755(18.40 \%)$ \\
Middle & $34,934(19.05 \%)$ \\
Richer & $37,225(20.30 \%)$ \\
Richest & $45,001(24.54 \%)$ \\
Risky sexual behavior
\end{tabular}

Risky sexual behavior

No risk

Some risk

High risk

HIV knowledge

Low knowledge

High knowledge

Comprehensive knowledge

Marital status

Unmaried

Maried

Number of sexual partners

One

More than one

Stigma indicator

\section{No stigma \\ Low stigma \\ Moderate stigma}

High stigma

Residence

Urban

Rural

Age at sex

Before 20 years
Table 2 Sociodemographic characteristics of the respondents in eastern Africa $(N=183,411)$ (Continued)

\begin{tabular}{ll}
\hline Variables & Frequency (\%) \\
\hline At 20 and after years & $74,878(40.83 \%)$ \\
Visit health facility & \\
No & $72,075(43.18 \%)$ \\
Yes & $94,857(56.82 \%)$ \\
Community illiteracy level & \\
High & $90,641(49.42 \%)$ \\
Low & $92,770(50.58 \%)$ \\
\hline
\end{tabular}

Operating Curve (ROC). These are plotted based on the probability of sensitivity and 1 - specificity. Accordingly, the AUC of the final model was $84.5 \%$ and indicated that the model's ability to predict HIV testing was good (Fig. 2).

\section{Factors associated with HIV testing}

For assessing factors associated with HIV testing, we consider the final model since it had the lowest deviance. In the multivariable multilevel analysis factors such as the age of respondent, marital status, educational level, HIV knowledge, HIV stigma indicator, risky sexual behavior and women who visit a health facility were positively associated with HIV testing coverage among reproductive-age women. While women from rich and richest households, having multiple sexual partners, being from rural dwellers, late initiation of sex and higher community illiteracy level had a lower chance of being tested for HIV. Women aged 20 years and above had higher odds of being tested for HIV compared with women of 15-19 years old. The odds of testing for HIV was $2.67(\mathrm{AOR}=2.67: 95 \% \mathrm{CI} ; 2.60,2.74)$ times higher for women visiting health centers in the last 12 months compared with their counterparts. Regarding educational level, the odds of testing for HIV was 2.30 ( $\mathrm{AOR}=2.30$ : 95\%CI; 2.22, 2.38), 2.39 (AOR $=2.39: 95 \% \mathrm{CI} ; 2.29,2.50)$ and $3.13(\mathrm{AOR}=3.13: 95 \% \mathrm{CI} ; 2.89,3.39)$ times higher for women with primary, secondary and higher educational level, respectively, compared to women with no formal education. Being from rich $(\mathrm{AOR}=0.93$ : $95 \% \mathrm{CI}$; $0.89,0.97)$ and richest $(\mathrm{AOR}=0.80: 95 \% \mathrm{CI} ; 0.76,0.84$ ) households had lower odds of being tested for HIV. Being married had $1.32(\mathrm{AOR}=1.32$ : $95 \% \mathrm{CI} ; 1.28,1.36)$ times more likely to be tested for HIV compared with their counterpart. Individuals who initiate sex after 20 years of age had 33\% (AOR $=0.67: 95 \% \mathrm{CI} ; 0.65,0.69)$ lower odds of being tested for HIV compared to those who initiate sex early. Regarding stigma, women with higher, moderate and low stigma scores had 1.56 $(\mathrm{AOR}=1.56: \quad 95 \% \mathrm{CI} ; 1.46, \quad 1.66), 2.24 \quad(\mathrm{AOR}=2.24$ : $95 \% \mathrm{CI} ; 2.16,2.32)$, and $2.27(\mathrm{AOR}=2.27: 95 \% \mathrm{CI} ; 2.19$, 


\section{Prevalence of HIV testing and counsling in eastern africa}

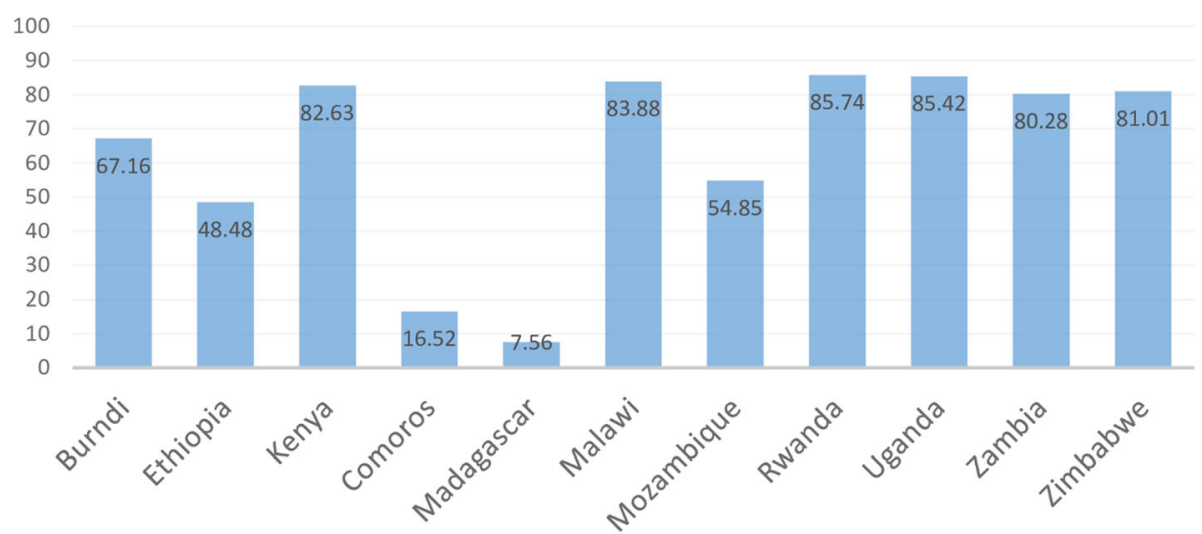

Fig. 1 Showing the prevalence of HIV testing across different countries

2.35) times higher odds of being tested for HIV compared to those with no stigma. Women with higher $(\mathrm{AOR}=6.44:$ 95\%CI: 6.21, 6.68) and comprehensive knowledge $(\mathrm{AOR}=10.7: 95 \% \mathrm{CI} ; 10.29,11.12)$ about HIV/AIDS had higher odds of being tested for HIV compared with women with low knowledge. Women having high $(\mathrm{AOR}=1.78$ : $95 \% \mathrm{CI} ; 1.67,1.90)$ and some risky sexual behavior $(\mathrm{AOR}=1.59$ : $955 \mathrm{CI} ; 1.53,1.66)$ had higher odds of being tested for HIV compared to women with no risky sexual behavior. Women with multiple sexual partners had a $36 \%$ lower chance of being tested for $\mathrm{HIV}$ (AOR $=0.64: 95 \% \mathrm{CI}$; 0.62, 0.66) as compared to their counterparts. Women from the rural areas had $31 \%(\mathrm{AOR}=0.69: 95 \% \mathrm{CI} ; 0.67,0.72$ ) lower odds of being tested for HIV compared with their counterparts. Being from communities with higher community illiteracy levels had 27\% (AOR =0.73: 95\%CI; 0.68, 0.78) lower odds of being tested for HIV compared with women from communities with lower community illiteracy levels (Table 4).

\section{Discussion}

The pooled prevalence of HIV testing in east Africa was $66.9 \%$ (95\%CI; 66.70, 67.13\%), which varies greatly from region to region. The regional variations in quality and access to HIV testing facilities as well as knowledge related to HIV / AIDS may be the reasons for the reported regional variations of HIV testing in eastern Africa [9, 14]. The prevalence reported in this study was in line with the report in Kenya [12]. The finding in this study was greater than the study conducted elsewhere $[3,16,23]$ and it was smaller than reports from different studies [9, 10]. The observed variations in the prevalence of HIV testing might be explained by cultural beliefs and lifestyle differences across regions [14]. Besides, the discrepancy might be due to the difference in quality and accessibility of HIV testing facilities [9, 14, 24, 25].

In this study age of respondent, multiple sexual partnerships, marital status, visiting health facility, stigmatized attitude towards HIV/AIDS, HIV knowledge, risky sexual behavior, residence, educational level, wealth status, age at first sex, and community illiteracy level were significant factors associated with HIV testing.

The odds of HIV testing was higher among married women compared with their counterpart. This finding was in agreement with the study done in Ethiopia [22]. This might be due to compulsory counseling and

Table 3 Random effect model and model fitness for the assessment of HIV testing among reproductive-age women in eastern Africa

\begin{tabular}{lllll}
\hline Parameter & Null model & Model I & Model II & Model III \\
\hline Intraclass correlation coefficient (ICC) & 0.10031 & 0.0692 & 0.0782476 & 0.066394 \\
Percentage change in variation (PCV) & Ref & 0.33 & 0.39 & 0.36 \\
Median odds ratio (MOR) & 1.77 & 1.6 & 1.65 & 1.58 \\
$\begin{array}{l}\text { Model comparison } \\
\quad\end{array} \quad$ & & & \\
$\quad$ Log likelihood & -113956.33 & -75036.661 & -113215.37 & -74814.426 \\
$\quad$ Deviance & 227912.66 & 150073.322 & 226420.47 & 149628.852 \\
\hline
\end{tabular}




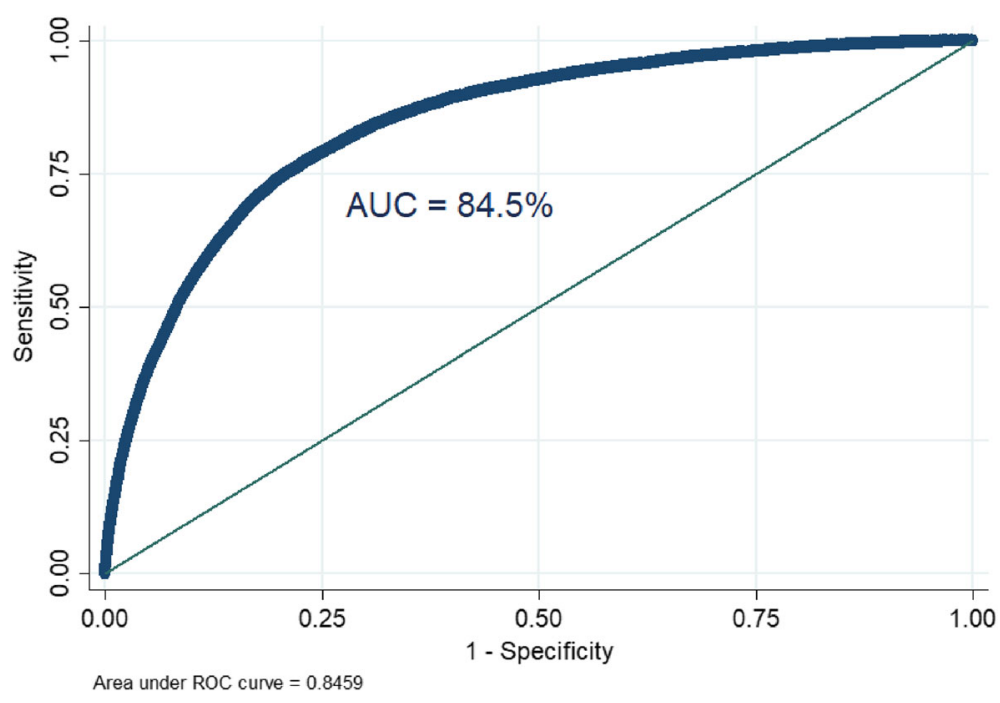

Fig. 2 Showing the area under the ROC curve

testing promotion for couples intending to get married by different organizations including religious groups [22]. Women who visit health care facilities had higher odds of being tested for HIV, which was supported by another study [16]. This might be because health professionals initiate people who visited health facilities for HIV testing [16].

In this study women from higher socioeconomic status had lower odds of being tested for HIV, which is contrary to another study [7]. This is justified by being rich may be associated with a greater awareness of risks and with reduced financial barriers to testing [26]. Women with primary and above educational levels had a higher chance of being tested for HIV, which is supported by different studies [16, 27]. The reason for this discrepancy might be as education can improve HIV knowledge as well as empowers women to make decisions to visit the health facility and use health services [28].

Women who had multiple sexual partners had less chance of being tested for HIV compared with their counterparts. However, the finding of this study was in contrast to another study [16]. This difference might be associated with individuals with a history of multiple sexual partnerships who might be fear of having HIV and have no interest to know their status. The study at hand revealed that women with higher and comprehensive knowledge about HIV had higher odds of being tested for HIV. This is supported by a study conducted in South Africa [13]. Different studies reported people with higher HIV-associated stigma scores had less chance of being tested for HIV. This is explained as people could be hesitant to test because the disclosure of a positive HIV test result may lead to loss of friendship, family relations, jobs and housing and health care due to stigmatization $[2,18,22]$. However, in the present study people with stigmatized attitudes had a higher chance of being tested for HIV and this might be explained by the variation in the cultural and socioeconomic status of the population included in this study.

In this study, women with risky sexual behavior had higher odds of being tested for HIV. This is supported by another study [22]. Individuals with risky sexual behavior live under persistent fear and uncertainty about their serostatus and are usually suspicious and worried that they might have infected with HIV. This urges them to develop habits of seeking VCT service [17].

Individuals who initiated sex early had a higher chance of being tested for HIV and this is supported by the study conducted in Malawi [14]. This might be explained as early age at first sexual intercourse is associated with a higher risk of acquiring the different sexually transmitted disease and risky sexual behaviors that may lead to a higher risk for HIV infection, which in turn enforce them to know their HIV status [29].

Women from rural dwellers had lower odds of being tested for HIV, which was supported by the study conducted in Ethiopia [16]. This may be justified by the better availability and accessibility of HIV testing facilities in urban settings compared with rural [30, 31]. Women from communities with higher illiteracy levels had less chance of being tested for HIV. This finding was supported by studies conducted in Ethiopia and Zambia [10, 16]. This might be associated with educational attainment may increase uptake of testing through increased recognition of the importance of knowing one's HIV status [20,32]. 
Table 4 The bivariable and multivariable multilevel binary logistic regression analysis of factors associated with HIV testing in East Africa in the final model

\begin{tabular}{|c|c|c|c|c|}
\hline \multirow[t]{2}{*}{ Variables } & \multicolumn{2}{|c|}{ Ever tested for HIV } & \multirow[t]{2}{*}{$\operatorname{COR}(95 \% \mathrm{Cl})$} & \multirow[t]{2}{*}{ AOR(95\%Cl) } \\
\hline & Yes & No & & \\
\hline \multicolumn{5}{|l|}{ Respondent age } \\
\hline $15-19$ & 15383 & 24122 & 1 & 1 \\
\hline $20-24$ & 25379 & 8738 & $4.70(4.55,4.86)$ & $3.67(3.53,3.82)^{*}$ \\
\hline $25-29$ & 25,043 & 6664 & $6.33(6.11,6.55)$ & $5.36(5.12,5.61)^{*}$ \\
\hline $30-34$ & 21074 & 5882 & $6.23(6.01,6.47)$ & $5.49(5.23,5.76)^{*}$ \\
\hline $35-39$ & 16333 & 5521 & $5.20(5.00,5.40)$ & $4.77(4.54,5.01)^{*}$ \\
\hline $40-44$ & 11673 & 4714 & $4.16(3.99,4.33)$ & $4.12(3.91,4.34)^{*}$ \\
\hline $45-49$ & 7860 & 4827 & $2.78(2.66,2.90)$ & $3.03(2.87,3.20)^{*}$ \\
\hline \multicolumn{5}{|l|}{ Visiting health facility } \\
\hline No & 34413 & 37624 & 1 & 1 \\
\hline Yes & 74386 & 20401 & $4.06(3.97,4.15)$ & $2.67(2.60,2.74)^{*}$ \\
\hline \multicolumn{5}{|l|}{ Highest educational level } \\
\hline No education & 17747 & 15253 & 1 & 1 \\
\hline Primary education & 61029 & 28085 & $1.84(1.79,1.89)$ & $2.30(2.22,2.38)^{*}$ \\
\hline Secondary education & 35471 & 15781 & $1.81(1.76,1.87)$ & $2.39(2.29,2.50)^{*}$ \\
\hline Higher education & 8488 & 1347 & $4.58(4.31,4.87)$ & $3.13(2.89,3.39)^{*}$ \\
\hline \multicolumn{5}{|l|}{ Wealth status } \\
\hline Poorest & 20082 & 12353 & 1 & 1 \\
\hline Poorer & 21473 & 12245 & $1.25(1.21,1.29)$ & 0.97 (0.93 1.02) \\
\hline Middle & 22840 & 12054 & $1.38(1.33,1.43)$ & $0.98(0.931 .02)$ \\
\hline Rich & 25606 & 11585 & $1.56(1.51,1.61)$ & $0.93(0.89,0.97)^{*}$ \\
\hline Richest & 32745 & 12231 & $1.71(1.66,1.76)$ & $0.80(0.76,0.84)^{*}$ \\
\hline \multicolumn{5}{|l|}{ Marital statues } \\
\hline Married & 69948 & 24745 & $1.99(1.95,2.03)$ & $1.32(1.28,1.36)^{*}$ \\
\hline Unmarried & 52799 & 35722 & 1 & 1 \\
\hline \multicolumn{5}{|l|}{ No of sexual partner } \\
\hline One & 52493 & 19907 & 1 & 1 \\
\hline More than one & 70254 & 40560 & $0.55(0.54,0.56)$ & $0.64(0.620 .66)^{*}$ \\
\hline \multicolumn{5}{|l|}{ HIV knowledge } \\
\hline Low knowledge & 7414 & 9619 & 1 & 1 \\
\hline Higher knowledge & 49482 & 22146 & $6.9(6.69,7.11)$ & $6.44(6.21,6.68)^{*}$ \\
\hline Comprehensive knowledge & 65773 & 15416 & $12.6(12.20,13.01)$ & $10.7(10.2911 .12)^{*}$ \\
\hline \multicolumn{5}{|l|}{ Stigma indicator } \\
\hline Higher stigma & 4375 & 3194 & $1.05(1.01,1.11)$ & $1.56(1.46,1.66)^{*}$ \\
\hline Moderate stigma & 25817 & 8414 & $2.30(2.24,2.37)$ & $2.24(2.16,2.32)^{*}$ \\
\hline Low stigma & 27813 & 7799 & $2.68(2.61,2.76)$ & $2.27(2.19,2.35)^{*}$ \\
\hline No stigma & 4905 & 1056 & 1 & 1 \\
\hline \multicolumn{5}{|l|}{ Residence } \\
\hline Urban & 38964 & 12404 & 1 & 1 \\
\hline Rural & 83783 & 48063 & $0.66(0.64,0.67)$ & $0.69(0.67,0.72)^{*}$ \\
\hline \multicolumn{5}{|l|}{ Risky sexual behavior } \\
\hline Higher risk & 7119 & 1805 & $2.21(2.10,2.33)$ & $1.78(1.67,1.90)^{*}$ \\
\hline
\end{tabular}


Table 4 The bivariable and multivariable multilevel binary logistic regression analysis of factors associated with HIV testing in East Africa in the final model (Continued)

\begin{tabular}{lllll}
\hline Variables & Ever tested for HIV & & COR(95\%Cl) & AOR(95\%Cl) \\
\cline { 2 - 4 } & Yes & No & $1.80(1.74,1.87)$ & $1.59(1.53,1.66)^{*}$ \\
\hline Some risk & 15518 & 4636 & 1 & 1 \\
No risk & 86043 & 43784 & & 1 \\
Age at sex & & & 1 & $0.67(0.65,0.69)^{*}$ \\
Before 20 years & 79591 & 29772 & $8.66(8.37,8.96)$ & 1 \\
At 20 and above years & 35500 & 9309 & & 1 \\
Community illiteracy level & & & $0.52(0.48,0.55)$ & $0.73(0.68,0.78)^{*}$ \\
Low & 64381 & 26126 & & \\
High & 58366 & 34341 & &
\end{tabular}

\section{Strength and limitation of the study}

The study was based on weighted nationally representative data from 11 eastern African countries with a large sample size. Also, the analysis used the multilevel analysis to accommodate the hierarchical nature of the DHS data. Moreover, since it is based on the national survey data, the study has the potential to give insight for policy-makers and program planners to design appropriate intervention strategies both at the national and regional levels. However, this study had limitations in that the DHS survey was based on respondents' self-report, this might have the possibility of recall bias. Besides, since this study was based on cross-sectional collected DHS data, we are unable to show the temporal relationship between HIV testing and independent variables.

\section{Conclusion}

The prevalence of HIV testing in this study was higher than the report from previous studies. Age of respondent, marital status, educational level, HIV knowledge, stigma indicator, risky sexual behavior, women who visit a health facility, early initiation of sex, wealth status, multiple sexual partnerships, residence and community illiteracy level were significantly associated with HIV testing among reproductive-age women. Therefore, there should be an integrated strategic plan to give education about methods of HIV transmission and the implication of HIV testing and counseling.

Also, it is instrumental to bringing behavioral change, reducing unprotected sex and helping to reduce early initiation of sex and avoidance of having multiple sexual partners. So all the stakeholders should have an integrated approach by giving special attention to the factors that hinder HIV testing to increase awareness regarding the benefit of HIV testing and counseling to control the spread of HIV/AIDS.

\section{Abbreviations}

Cl: Confidence Interval; CSA: Central Statistical Agency; DHS: Demographic Health Survey; EA: Enumeration Area; ICC: Intraclass correlation coefficient; LLR: likelihood Ratio; WHO: World Health Organization

\section{Acknowledgments}

We greatly acknowledge MEASURE DHS for granting access to the Demographic and Health Surveys data.

\section{Authors' contributions}

GAT, MGW, ABT conceived the study. GAT, MGW, ABT analyzed the data. GAT, MGW, ABT, drafted the manuscript and reviewed the article. GAT, MGW ABT extensively reviewed the article. All authors read and approved the final manuscript.

\section{Funding}

No funding was obtained for this study.

Availability of data and materials

Data is available online and you can access it from www.measuredhs.com.

\section{Declarations}

Ethics approval and consent to participate

Since the study was a secondary data analysis of publically available survey data from the MEASURE DHS program, ethical approval and participant consent were not necessary for this particular study. We requested DHS Program and permission was granted to download and use the data for this study from http://www.dhsprogram.com. The Institution Review Board approved procedures for DHS public-use datasets do not in any way allow respondents, households, or sample communities to be identified. There are no names of individuals or household addresses in the data files.

\section{Consent for publication}

Not applicable since the study was a secondary data analysis already collected by CSA.

\section{Competing interests}

Authors declare that they have no conflict of interest.

\section{Author details}

'Department of Human Anatomy, College of Medicine and Health Science, School of Medicine, University of Gondar, Gondar, Ethiopia. ${ }^{2}$ Department of Epidemiology and Biostatistics, Institute of Public Health, College of Medicine and Health Sciences, University of Gondar, Gondar, Ethiopia. 
Received: 27 November 2020 Accepted: 15 June 2021

Published online: 29 June 2021

\section{References}

1. UNAIDS W. Global AIDS response progress reporting 2015. Geneva: UNAIDS; 2015

2. Paulin HN, Blevins $M$, Koethe $J R$, Hinton $N$, Vaz LME, Vergara AE, et al. HIV testing service awareness and service uptake among female heads of household in rural Mozambique: results from a province-wide survey. BMC Public Health. 2015;15(1):132. https://doi.org/10.1186/s12889-015-1388-z.

3. Asaolu IO, Gunn JK, Center KE, Koss MP, Iwelunmor JI, Ehiri JE. Predictors of HIV testing among youth in sub-Saharan Africa: a crosssectional study. PLoS One. 2016;11(10):e0164052. https://doi.org/10.1371/ journal.pone.0164052

4. Webb D. HIV and AIDS in Africa: Pluto Press; 1997.

5. Avert. HIV and AIDS in East and Southern Africa regional overview. 2017.

6. Global H. AIDS statistics-2019 fact sheet (2019). 2020.

7. Leta T, Sandøy I, Fylkesnes K. Factors affecting voluntary HIV counselling and testing among men in Ethiopia: a cross-sectional survey. BMC Public Health. 2012;12(1):438. https://doi.org/10.1186/1471-2458-12-438.

8. World Health O. HIV testing and counselling : the gateway to treatment, care and support. Geneva: World Health Organization; 2003.

9. Salima N, Leah E, Stephen L. HIV testing among women of reproductive age exposed to intimate partner violence in Uganda. Open Public Health J. 2018;11(1):275-87.

10. Muyunda B, Mee P, Todd J, Musonda P, Michelo C. Estimating levels of HIV testing coverage and use in prevention of mother-to-child transmission among women of reproductive age in Zambia. Arch Public Health. 2018; 76(1):80. https://doi.org/10.1186/s13690-018-0325-x

11. Muyunda B, Musonda P, Mee P, Todd J, Michelo C. Educational attainment as a predictor of HIV testing uptake among women of child-bearing age: analysis of 2014 demographic and health survey in Zambia. Front Public Health. 2018;6:192.

12. Nall A, Chenneville T, Rodriguez LM, O'Brien JL. Factors affecting HIV testing among youth in Kenya. Int J Environ Res Public Health. 2019;16(8):1450. https://doi.org/10.3390/ijerph16081450.

13. Peltzer K, Matseke G. Determinants of HIV testing among young people aged 18-24 years in South Africa. Afr Health Sci. 2013;13(4):1012-20. https:// doi.org/10.4314/ahs.v13i4.22.

14. Mandiwa C, Namondwe B. Uptake and correlates of HIV testing among men in Malawi: evidence from a national population-based household survey. BMC Health Serv Res. 2019;19(1):203.

15. Kaai S, Bullock S, Burchell AN, Major C. Factors that affect HIV testing and counseling services among heterosexuals in Canada and the United Kingdom: an integrated review. Patient Educ Couns. 2012;88(1):4-15. https://doi.org/10.1016/j.pec.2011.11.011

16. Bekele YA, Fekadu GA. Factors associated with HIV testing among young females; further analysis of the 2016 Ethiopian demographic and health survey data. PLoS One. 2020;15(2):e0228783. https://doi.org/10.1371/journal. pone.0228783

17. Khamisa N, Mokgobi M. Risky sexual behaviour and human immunodeficiency virus (HIV) and acquired immune deficiency syndrome (AIDS) among healthcare workers. South Afr J HIV Med. 2018;19(1):744.

18. Young SD, Bendavid E. The relationship between HIV testing, stigma, and health service usage. AIDS Care. 2010;22(3):373-80. https://doi.org/10.1080/ 09540120903193666

19. Kautako-Kiambi M, Ekila MB, Kama-Lemba S, Wumba R, Aloni MN. Voluntary counseling and testing for HIV in rural area of Democratic Republic of the Congo: knowledge, attitude, and practice survey among service users. J Trop Med. 2015:2015:281093.

20. Martell AN. Association of HIV testing, educational attainment, and age among black and non-black men; 2014

21. Mugabe D, Bhatt N, Carlucci JG, Gudo ES, Gong W, Sidat M, et al. Selfreported non-receipt of HIV test results: a silent barrier to HIV epidemic control in Mozambique. PLoS One. 2019;14(10):e0224102. https://doi.org/1 0.1371/journal.pone.0224102

22. Erena AN, Shen G, Lei P. Factors affecting HIV counselling and testing among Ethiopian women aged 15-49. BMC Infect Dis. 2019:19(1):1076. https://doi.org/10.1186/s12879-019-4701-0.
23. Fikadie G, Bedimo M, Alamrew Z. Prevalence of voluntary counseling and testing utilization and its associated factors among Bahirdar University students. Adv Prev Med. 2014;2014:906107.

24. Control CfD, Prevention. Advancing HIV prevention: new strategies for a changing epidemic--United States, 2003. MMWR Morb Mortal Wkly Rep. 2003;52(15):329.

25. Adler NE, Newman K. Socioeconomic disparities in health: pathways and policies. Health Aff. 2002;21(2):60-76. https://doi.org/10.1377/hlthaff.21.2.60.

26. Obermeyer CM, Neuman M, Hardon A, Desclaux A, Wanyenze R, Ky-Zerbo $\mathrm{O}$, et al. Socio-economic determinants of HIV testing and counselling: a comparative study in four a frican countries. Tropical Med Int Health. 2013; 18(9):1110-8. https://doi.org/10.1111/tmi.12155.

27. Ssebunya RN, Wanyenze RK, Namale L, Lukolyo H, Kisitu GP, NahiryaNtege $P$, et al. Prevalence and correlates of HIV testing among adolescents 10-19 years in a post-conflict pastoralist community of Karamoja region, Uganda. BMC Public Health. 2018;18(1):612. https://doi. org/10.1186/s12889-018-5544-0.

28. Jamison EA, Jamison DT, Hanushek EA. The effects of education quality on income growth and mortality decline. Econ Educ Rev. 2007;26(6):771-88. https://doi.org/10.1016/j.econedurev.2007.07.001.

29. Ghebremichael M, Larsen U, Paintsil E. Association of age at first sex with HIV-1, HSV-2, and other sexual transmitted infections among women in northern Tanzania. Sex Transm Dis. 2009;36(9):570-6. https://doi.org/10.1 097/OLQ.0b013e3181a866b8.

30. Spasojevic N, Vasilj I, Hrabac B, Celik D. Rural - Urban differences in health care quality assessment. Mater Soc. 2015;27(6):409-11. https://doi.org/10.54 55/msm.2015.27.409-411.

31. Swann M. Economic strengthening for HIV prevention and risk reduction: a review of the evidence. AIDS Care. 2018;30(sup3):37-84.

32. Teklehaimanot HD, Teklehaimanot A, Yohannes M, Biratu D. Factors influencing the uptake of voluntary HIV counseling and testing in rural Ethiopia: a cross sectional study. BMC Public Health. 2016;16(1):239. https:// doi.org/10.1186/s12889-016-2918-z.

\section{Publisher's Note}

Springer Nature remains neutral with regard to jurisdictional claims in published maps and institutional affiliations.

Ready to submit your research? Choose BMC and benefit from:

- fast, convenient online submission

- thorough peer review by experienced researchers in your field

- rapid publication on acceptance

- support for research data, including large and complex data types

- gold Open Access which fosters wider collaboration and increased citations

- maximum visibility for your research: over $100 \mathrm{M}$ website views per year

At BMC, research is always in progress.

Learn more biomedcentral.com/submission 